\title{
Gravidez em cárcere: As consequências da ausência de pré-natal na saúde da mulher em situação de privação de liberdade
}

\author{
Pregnancy in Prison: The consequences of the absence of prenatal care on the health of women in \\ situations of deprivation of liberty
}

Embarazo en prisión: las consecuencias de la ausencia de cuidados prenatales en la salud de las mujeres en situación de privación de libertad

Recebido: 13/07/2021 | Revisado: 19/07/2021 | Aceito: 27/07/2021 | Publicado: 03/08/2021

\author{
Amanda Cunha Lima Lisboa \\ ORCID: https://orcid.org/0000-0002-1911-3481 \\ Centro Universitário Metropoltano da Amazônia, Brasil \\ E-mail:amandacunhalima_lisboa@hotmal.com \\ Gabrielle da Silva Lobato \\ ORCID: https://orcid.org/0000-0002-2225-4963 \\ Centro Universitário Metropoltano da Amazônia, Brasil \\ E-mail: gabriellelobato83@gmail.com \\ Isabelle Soria Galvarro Franco \\ ORCID: https://orcid.org/0000-0002-6478-9763 \\ Centro Universitário Metropoltano da Amazônia, Brasil \\ E-mail: isabellefranco8@hotmail.com \\ Yasmin Castro da Rocha \\ ORCID: https://orcid.org/0000-0001-9594-0385 \\ Centro Universitário Metropoltano da Amazônia, Brasil \\ E-mail: yasminncrocha@gmail.com \\ Deusa Merian da Silva Brito \\ ORCID: https://orcid.org/0000-0002-2397-4372 \\ Centro Universitário Metropoltano da Amazônia, Brasil \\ E-mail: meriamsp@gmail.com \\ Maria Helena Rodrigues de Mendonça \\ ORCID: https://orcid.org/0000-0003-0571-0565 \\ Centro Universitário Metropoltano da Amazônia, Brasil \\ E-mail: helenarmendonca@gmail.com
}

\begin{abstract}
Resumo
Introdução: inicialmente, destaca-se a situação de cárcere relacionada às gestantes em privação de liberdade, com condições insalubres de higiene, acesso a um pré-natal inadequado durante a gravidez, dificuldade de acesso a enfermarias, ambulatórios e atendimento médico adequado. Ressalta-se também a questão do amparo à mulher em período gestacional, de acordo com a Constituição Federal Brasileira, especificamente na Política Nacional de Atenção a Mulheres em Situação de Liberdade (PNAMPE). O referido trabalho tem como objetivo analisar os pontos acerca da assistência ao pré-natal da mulher, em período gestacional, quando ela se encontra em regime de privação de liberdade. Justificativa: A realização dessa pesquisa ocorreu em razão da situação prisional do Brasil ser preocupante, principalmente no estado do Pará, em que o quantitativo da população carcerária feminina é maior que a capacidade suportada. A superlotação no ambiente prisional dificulta ações efetivas para uma atenção mais individual às detentas e à efetivação dos direitos supracitados previstos na Constituição Federal. Metodologia: Tratase de uma revisão integrativa de literatura em textos completos dos últimos 10 anos. Resultados: é possível notar a situação alarmante que as gestantes enfrentam em unidades prisionais não ofertantes de assistência ao Pré-natal adequadamente. Ao pesquisar sobre essa temática foi evidenciada a ausência de artigos, nas principais bases de dados, relacionados às questões de saúde da gestante encarcerada. Conclusão: concluímos que as condições insalubres das casas penais trazem sérios riscos à saúde das crianças que são geradas e que nascem nessa situação de privação de liberdade e que as mulheres gestantes não recebem a atenção básica de direito durante o ciclo da gestação e puerpério, havendo necessidade de um trabalho intersetorial e interprofissional para garantir o acesso à política pública com qualidade.
\end{abstract}

Palavras-chave: Mulher; Pré-natal; Gestação; Privação de liberdade; Penitenciária.

\section{Abstract}

Introduction: initially, the situation of imprisonment related to pregnant women in prison is highlighted, such as unhealthy hygiene conditions, access to inadequate prenatal care during pregnancy, difficulty of access to wards, 
outpatient clinics and adequate medical care. We also highlight the issue of support for women during pregnancy, according to the Brazilian Federal Constitution, specifically in the National Policy of Attention to Women in Situations of Freedom (PNAMPE). This work aims to analyze the points about prenatal care for women in pregnancy when they are in a regime of deprivation of liberty. Justification: This research was conducted due to the worrisome prison situation in Brazil, especially in the state of Pará, where the number of women in prisons is greater than the supported capacity. The overcrowding in the prison environment hinders effective actions for a more individual attention to female prisoners and the realization of the aforementioned rights provided for in the Federal Constitution. Methodology: This is an integrative review of literature in full texts from the last 10 years. Results: It is possible to note the alarming situation that pregnant women face in prison units that do not offer prenatal care adequately. When researching on this theme it was evidenced the absence of articles, in the main databases, related to health issues of pregnant women in prison. Conclusion: we conclude that the unhealthy conditions of the penitentiaries bring serious risks to the serious risks to the health of children who are generated and born in this situation of deprivation of liberty and that pregnant women do not receive the basic attention of right during pregnancy and puerperium cycle, with the need for intersectoral and interprofessional work to ensure access to public policy with quality.

Keywords: Women; Prenatal; Pregnancy; Deprivation of liberty; Penitentiary.

\section{Resumen}

Introducción: inicialmente, se destaca la situación de carencia relacionada con las gestantes en privación de libertad, como a las condiciones insalubres de higiene, el acceso a un prenatal inadecuado durante la gestación, la dificultad de acceso a enfermerías, ambulatorios y atención médica adecuada. También se destaca la cuestión del apoyo a las mujeres en período de gestación, según la Constitución Federal brasileña, específicamente en la Política Nacional de Atención a las Mujeres en Situación de Libertad (PNAMPE). Este trabajo tiene como objetivo analizar los puntos sobre la atención prenatal de la mujer en el embarazo, cuando se encuentra en un régimen de privación de libertad. Justificación: Esta investigación se realizó porque la situación carcelaria en Brasil es preocupante, especialmente en el estado de Pará, donde la cantidad de población carcelaria femenina es mayor que la capacidad soportada. El hacinamiento en el medio carcelario dificulta las acciones efectivas para una atención más individualizada de las presas y la realización de los mencionados derechos previstos en la Constitución Federal. Metodología: Se trata de una revisión integradora de la literatura en textos completos de los últimos 10 años. Resultados: es posible constatar la situación alarmante a la que se enfrentan las gestantes en las unidades penitenciarias que no ofrecen asistencia prenatal de forma adecuada. Al investigar sobre este tema, se evidenció la ausencia de artículos, en las principales bases de datos, relacionados con las cuestiones de seguridad de la gestora encarcelada. Conclusión: llegamos a la conclusión de que las condiciones insalubres de los centros penitenciarios traen graves riesgos para la salud de los niños que se generan y que nacen en esta situación de privación de libertad y que las mujeres embarazadas no reciben la atención básica de derecho durante el ciclo de gestación y puerperio, con la necesidad de un trabajo intersectorial e interprofesional para garantizar el acceso a las políticas públicas con calidad.

Palabras clave: Mujeres; Prenatal; Embarazo; Privación de libertad; Penitenciario.

\section{Introdução}

A Constituição Federal positiva é a base da assistência à saúde gestacional da mulher, logo, é o princípio basilar da Política Nacional de Atenção a Mulheres em situação de privação de liberdade e egressas no sistema prisional (PNAMPE), a qual tem por objetivo a prevenção de todos os tipos de violência contra estas e a humanização das condições do cumprimento da pena, com a ajuda e articulação de todos os setores do governo (Brasil, 1988. Isso significa que cada penitenciária passou a ser um ponto da Rede de Atenção à Saúde (RAS) com todos os seus componentes e, consequentemente, a gestante, em questão, deve ser inscrita na Rede Cegonha para receber todos os cuidados que necessita e que essa rede pode oferecer, desde o pré-natal até o aleitamento materno (Brasil, 2014).

O Plano Nacional de Saúde no Sistema Penitenciário (PNSSP), criado a partir do Plano Nacional de Saúde (PNS), através das diretrizes dos direitos humanos que fomenta o direito à cidadania, trouxe a inclusão da população carcerária no Sistema Único de Saúde (SUS), consistindo na união sistemática de metodologias inclusivas para tais pessoas obedecendo princípios basilares como os supracitados (Ministério da Saúde, 2005; Ministério da Saúde, 2016).

Dessa forma, no que tange à situação da saúde das mulheres presas, é notório um índice elevado de determinadas 
doenças pela ausência de tratamentos preventivos, posto que, o enfoque dos planos sobrescritos ao incentivo de movimentos educacionais voltados para o uso de contraceptivos, evitando uma gravidez indesejada, bem como, para a possível estagnação ou diminuição do índice de transmissão de Infecção Sexualmente Transmissível (IST), como o Vírus da Imunodeficiência Humana (HIV), por exemplo, é insuficiente ou inexistente (Mourão, et al. 2015). Tal hipossuficiência do sistema e ausência do pré-natal estão, diretamente, ligados ao aumento de síndromes congênitas.

A justificativa dessa pesquisa refere-se à situação prisional do Brasil ser preocupante, principalmente no estado do Pará, uma vez que o departamento penitenciário nacional (DEPEN) através dos indicadores do Sistema Integrado de Informações Penitenciárias (InfoPen) levantou em junho de 2012, que a população carcerária feminina era de 810 (oitocentas e dez) pessoas, sendo a capacidade de 578 (quinhentas e setenta e oito) vagas Dessa forma, observa-se também a característica de superlotação no ambiente prisional, o que dificulta ações efetivas para uma atenção mais individual às detentas e à efetivação dos direitos supracitados previstos na Constituição Federal (Justiça Federal, 2014).

Essa pesquisa tem como objetivo analisar a assistência ao pré-natal de mulheres privadas de liberdade. Diante do exposto, pergunta-se: as grávidas em cárcere privado estão sendo assistidas pelo seu direito ao pré-natal?

\section{Metodologia}

Trata-se de uma Revisão Integrativa da Literatura, de origem qualitativa, que se utilizou de 24 literaturas. Este método é capaz de abranger a sistemática de levantamento de informações bibliográficas e/ou eletrônicas, específicas, como fonte para criteriosa análise e, consequente, síntese quantitativa das seleções retiradas a luz do tema.

A pergunta norteadora deste estudo foi: "Como ocorre a assistência pré-natal a mulheres em privação de liberdade no Brasil?”. A pesquisa bibliográfica ocorreu através do motor de busca Biblioteca Virtual em Saúde (BVS), considerando as seguintes bases de dados: Scientific Electronic Library Online (SciELO), Sistema Online de Busca e Análise de Literatura Médica (MEDLINE), Literatura Latino-Americana e do Caribe em Ciências da Saúde (LILACS) e Base de Dados de Enfermagem (BDENF). Para filtrar as buscas, utilizaram-se 3 (três) descritores oficializados pelos Descritores em Ciências da Saúde (DECS), individualmente e com as combinações dos boleadores AND: Cuidado Pré-Natal AND Penitenciárias AND Saúde pública.

\subsection{Critério de inclusão e exclusão}

Os critérios de inclusão foram: artigos que possuíam relação mais direta à temática, ou seja, que demonstrassem a realidade brasileira; disponibilizados de forma gratuita e publicados entre os anos de 2011 a 2021. Os critérios de exclusão foram: Artigos incompletos e ou repetidos; aqueles que não se relacionavam diretamente à temática e os que tiveram a publicação paga.

\section{Referencial Teórico}

\subsection{A relação das mulheres com a criminalidade}

Em um sistema penitenciário é notória a prevalência da discriminação das mulheres, e analisando os tipos de crimes praticados por elas, os quais são responsáveis pela situação do encarceramento, se distinguem dos realizados por homens, já que, raramente a mulher pratica um crime violento. Os principais motivos do aprisionamento das mulheres são por causa do envolvimento com substâncias ilícitas, evidenciando assim que fatores econômicos interferem diretamente na vida feminina e consequentemente as direcionam à marginalização (Davim e Lima, 2016).

Por conseguinte, os fatores que elevam as taxas de criminalidade feminina, conforme Makki e Santos (2010): 
Diante de tantos direitos garantidos constitucionalmente, Santos (2008), salienta que na realidade são evidenciados índices sociais demonstrando a saúde pública com deficiência de profissionais, estabelecimentos e equipamentos; a vida humana sofrendo atentados de toda a ordem; a educação pública lutando contra os baixos índices de frequência e qualidade no ensino; a segurança pública sendo ameaçada pelos chefes do crime organizado; as vagas de trabalho diminuindo e a mão de obra aumentando; o judiciário abarrotado de processos com insuficiente contingente de juízes; a infância sendo violentada e prostituída. Todos esses fatores pertencem ao ambiente vivido pela população, promovendo influências dentro do dia a dia tornando a população mais conivente e enrijecida diante de tais fatos. Em um âmbito geral, quando se estuda a população carcerária, seja ela feminina ou masculina, é impossível fugir da análise do fator que potencializou a imersão destes indivíduos no mundo do crime. Então se entra em um assunto muito complexo, pois a sociedade é um nicho de acontecimentos que convergem entre si, perfazendo consequências entre ações e reações, gerando desta forma um ciclo impetuoso e destrutivo.

No que se refere ao ingresso das mulheres na criminalidade, de acordo com Davim e Lima (2016), é preciso compreender, primeiramente, os fatores marcantes da infância de cada uma, sendo prevalente a grande exposição a situações de abandono, visto que os pais delas, muitas das vezes, precisaram trabalhar integralmente para assegurar o sustento da família. Frente a essa ausência, essas mulheres, quando meninas, ficaram à mercê de ensinamentos externos que influenciaram na formação do caráter.

Além dessa situação, precisaram lidar com o desamparo financeiro, limitando o progresso social e forçando-as a precocemente buscarem pelo próprio sustento, ocasionando a desistência dos estudos e a aceitação por subempregos a fim de alcançarem uma renda. Assim, essas mulheres, ao se tornarem mães, acabam recorrendo a meios ilícitos para assegurar a subsistência dos filhos. Nesse cenário, por mais que homens e mulheres sejam expostos a uma mesma realidade, as mulheres ainda enfrentam os aspectos culturais específicos do gênero, como serem abusada sexualmente quando mais novas, a gravidez precoce e a violência doméstica (Ferreira, 2020).

Sobre a ocorrência das mulheres na criminalidade, conforme Queiroz (2015, p. 36):

Em geral, é gente esmagada pela penúria, de áreas urbanas, que buscam o tráfico como sustento. São, na maioria, negras e pardas, mães abandonadas pelo companheiro e com ensino fundamental incompleto. Segundo o Ministério da Justiça, entre 2007 e 2012, a criminalidade cresceu $42 \%$ entre as mulheres — ritmo superior ao masculino. Uma tese em voga entre ativistas da área é a de que a emancipação da mulher como chefe da casa, sem a equiparação de seus salários com os masculinos, tem aumentado a pressão financeira sobre elas e levado mais mulheres ao crime no decorrer dos anos.

Dessa maneira, o encarceramento segue um tipo de padrão da sociedade, em que as mulheres, antes de serem intituladas como criminosas, foram vítimas do meio social, as quais estavam inseridas, já que nasceram diante da criminalidade e se desenvolveram nesse âmbito. Em inúmero dos casos, de mulheres que se envolvem no crime, ou elas já possuíam algum membro da família encarcerado, ou ainda, enquanto adolescente, tiveram que lidar com medidas socioeducativas (Barbosa, 2020).

\subsection{A situação das mulheres em cárcere privado no Brasil}

Nas regiões brasileiras, as periferias comportam os maiores polos responsáveis por tráfico de drogas e isso se deve ao sistema social, que permite essa concentração nessas localidades das grandes cidades. Portanto, as mulheres que nascem nesses locais recebem maiores influências negativas, pois possuem grandes chances de desenvolverem um relacionamento com homens que estejam inseridos no mundo do crime, caracterizando assim um importante fator de ingresso feminino na criminalidade, o envolvimento amoroso com alguém que já era praticante de ações delituosas (Queiroz, et al. 2015).

Em âmbito nacional, segundo o Levantamento Nacional de Informações Penitenciárias (INFOPEN), até dezembro 2019 o Brasil possuía 748.009 pessoas privadas de liberdade (PPL), entre essas, 362.547 (48,5\%) encontram-se em regime fechado, $222.558(29,75 \%)$ são os presos provisoriamente, 133.408 (17,84\%) em regime semiaberto e 25.137 (3,36\%) em regime aberto. Existem 755.274 unidades prisionais no Brasil, em que $99 \%$ dessas são do sistema penitenciário público e $1 \%$ 
são das parcerias com algumas instituições filantrópicas (Gomes, et al. 2020).

A respeito das unidades prisionais, 96,3\% são para os homens, já que correspondem à maioria (95\%) dos indivíduos privados de liberdade. Entretanto, não são todas essas unidades que estão ativas no país, uma vez que, ainda há a existência das cadeias mistas com delegacias de polícia que na maioria dos casos não comportam os presos. Diante dessa situação, se essas unidades,em totalidade, estivessem disponíveis, não se enfrentaria esse déficit enorme das vagas em penitenciárias (Gomes, et al. 2020).

Conforme Carvalho e Freitas (2016), são registradas situações deprimentes sobre os direitos humanos serem violados em presídios do Brasil, marcados pela presença de mulheres e homens em uma mesma cela, sem acesso a produtos à higiene

básica, e no caso das mulheres, sem produtos específicos que atendam suas questões biológicas, como exemplo os absorventes higiênicos e os medicamentos para alívio das dores de cólicas menstruais (Carvalho e Fretas, 2016).

A título de exemplificação da realidade enfrentada por essas mulheres encarceradas, Wermuth e Nielsson (2019) expuseram uma situação de uma presidiária do estado do Rio de Janeiro, que estava grávida e o nascimento do filho ocorreu enquanto ela estava sozinha, pois se encontrava em regime de isolamento. Essa mulher somente foi assistida após o parto, quando já estava carregando o filho nos braços, o qual ainda estava conectado a ela pelo cordão umbilical, e após isso teve que retornar ao isolamento e o filho foi encaminhado a um abrigo (Wermuth e Nielsson (2019).

Desse modo, pode-se perceber como os direitos dessas mulheres privadas de liberdade são violados. No que se refere às políticas públicas, relacionadas à situação de encarceramento feminino, Wermuth e Nielsson (2019, p. 98), afirmam que:

Há, desta forma, um déficit histórico em relação ao planejamento e à execução de políticas públicas voltadas ao coletivo feminino nas prisões, uma vez que a maioria das políticas penitenciárias foi pensada para a população majoritária, qual seja, a masculina. Em razão deste cenário, ainda hoje, milhares de mulheres vivem gestações, partose maternidades precárias, e seus filhos formam parcela invisível da população prisional.

A realidade em unidades prisionais engloba inúmeras e preocupantes violações dos direitos humanos, como por exemplo: a ausência do acompanhamento pré-natal para as gestantes, ocasionando transmissões de doenças aos filhos; a não realização de consultas médicas às mulheres grávidas, acontecendo assim a ocorrência de partos no interior da instituição prisional; os abusos em ambiente hospitalar; o isolamento das presas; a interrupção abrupta do contato da mãe com o filho e a manutenção das crianças em celas (Wermuth e Nielsson (2019). A Figura 1 a seguir demonstra o quantitativo de mulheres que foram aprisionadas nos últimos 20 anos no Brasil (Ministério da Justiça e Segurança Pública, 2020): 
Figura 1: Quantitativo de aprisionamento feminino nos últimos 20 anos no Brasil.

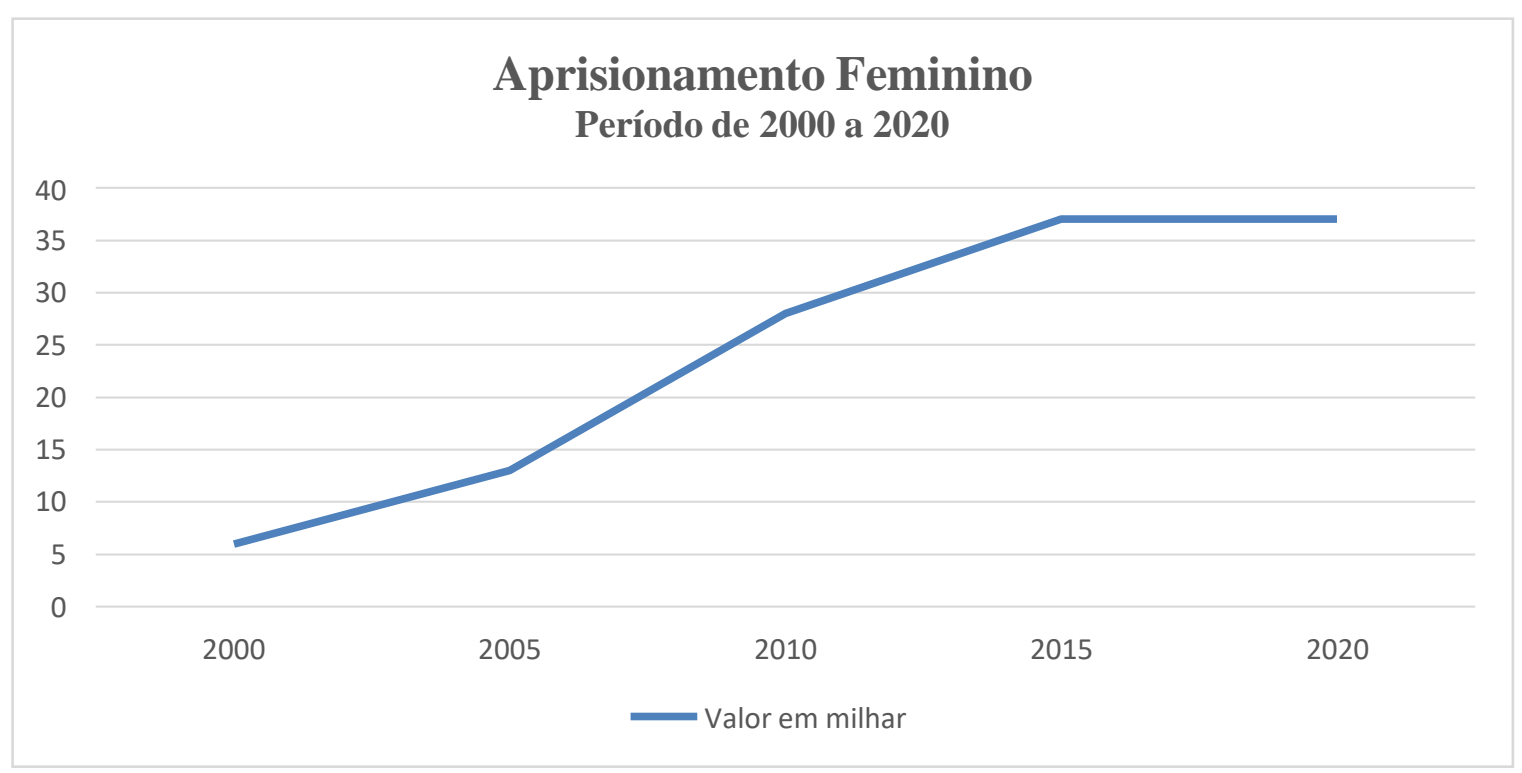

Fonte: Adaptado de Levantamento Nacional de Informações Penitenciárias. Ministério da Justiça (2020).

O crescimento da criminalidade e do encarceramento de mulheres no Brasil é preocupante. Sendo importante considerar que a mulher, diferentemente do homem, precisa se adaptar às unidades prisionais que foram construídas sem um planejamento acerca das particularidades femininas, principalmente no que se refere às questões relacionadas à sexualidade, saúde e maternidade. Assim, os maiores desafios para a mulher encarcerada se relacionam ao fato de precisar lidar com uma péssima estruturação do âmbito prisional para o atendimento das suas necessidades (Barbosa, et al. 2020).

O encarceramento feminino é uma condição capaz de gerar uma dupla punição, a qual é agravada quando a mulher se encontra grávida ou ao ter que exercer a maternidade no espaço prisional. Apesar das políticas públicas e as intervenções da legislação acerca da situação enfrentada por essas mulheres, evidencia-se que, em razão da cultura punitivista do encarceramento, a mulher, por ser criminosa, é vista como não merecedora de benefícios, ou ainda de exercer a gravidez e a maternidade longe do âmbito prisional. A figura 2 a seguir demonstra a situação da maternidade no Brasil das mulheres em cárcere privado: 
Figura 2: A retratação da maternidade em unidades prisionais do Brasil.

\section{Faixa etária dos filhos que estão no estabelecimento no periodo de janeiro a junho de 2020}

\author{
Total de filhos: 1.850 \\ Total de lactantes: 106 \\ Quantidade de gestantes / $: 176$
parturientes
}

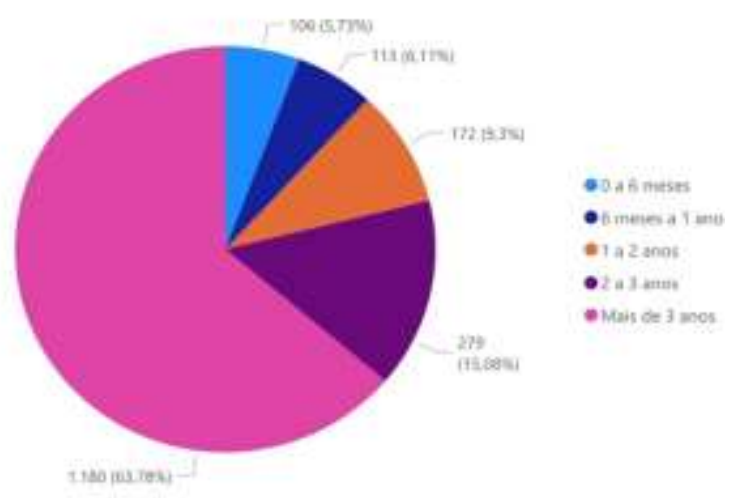

\begin{abstract}
Aplicável apenas para unidades prisionais com mulheres excluindo-se os presos que não sob tutela dos Sistemas Penitenciários
\end{abstract}

Fonte: Adaptado de Levantamento Nacional de Informações Penitenciárias. Ministério da Justiça (2020).

Desse modo, dentro do ambiente carcerário, as mulheres lidam com a violação constante dos direitos e sofrem em caráter físico e psicológico, principalmente as gestantes que não possuem acessibilidade a nenhum atendimento específico. Além disso, ainda lidam com a superlotação e as condições precárias que são oferecidas. Essa situação carcerária no Brasil confronta os princípios constitucionais, essencialmente o da dignidade da pessoa humana, despertando a atenção e preocupação à adoção de políticas públicas que sejam mais eficazes (Barbosa, et al. 2020).

\subsection{A importância do pré-natal à gestante em cárcere privado}

A assistência ao pré-natal diz respeito a um conjunto de ações importantes acerca dos cuidados, condutas e procedimentos que são realizados para o bem estar biopsicossocial da gestante. Esta precisa ser assistida desde a concepção até o início do trabalho de parto, a fim de garantir a identificação ou prevenção de possíveis complicações relacionadas à gestação, bem como a garantia da saúde materna, a promoção de um bom desenvolvimento do feto, a redução das taxas de morbimortalidade materna e neonatal e ainda a preparação dos pais para a paternidade (Silva e Cardoso, 2020).

Os diversos exames clínicos e laboratoriais que são solicitados e feitos durante as consultas do pré-natal permitem a identificação de situações que prejudicam a saúde da gestante e a possibilidade de agir de forma imediata para evitar agravamentos durante a gestação. Além disso, essa assistência possibilita a chance da realização de ações educativas, como as orientações para as gestantes e seus parceiros, através de palestras dadas em grupos ou individualmente em consultas. É uma ótima oportunidade do profissional de saúde estabelecer vínculos de confiança e segurança com a gestante (Silva e Cardoso, 2020).

O pré-natal tem um importante significado à gestante, representando a chance de acompanhar o desenvolvimento do feto; elucidar as dúvidas, temores e os sentimentos que decorrem da gravidez, do parto e da maternidade e ainda de buscar pelo apoio profissional que precisa. Ao se referir à realidade das mulheres grávidas privadas de liberdade, o que elas vivenciam é extremamente cruel, uma vez que além de estarem presas, precisam lidar com o sofrimento dos próprios filhos, ainda nos ventres. A assistência durante o pré-natal, o parto e a amamentação, ocorrem de forma errada, por isso, muitas vezes, são ineficazes, ocasionando riscos tanto às grávidas como também para os fetos que estão sendo formados (Santana, Oliveira e 
Bispo, et al. 2016).

Na pesquisa de Santana, Oliveira e Bispo (2016, p. 8), foram questionadas algumas gestantes encarceradas sobre a qualidade da assistência do pré-natal, então as grávidas, unanimemente, definiram como: "horrível", demonstrando a insatisfação, o medo e a insegurança delas diante dessas ações do pré-natal. A seguir dois relatos delas:

"Aqui é horrivel! A gente não tem atendimento médico, a central da casa nunca está disponível para a gente. Só lá no presídio masculino, eles têm médico a hora que precisar. Você passa mal, a médica nem lhe olha. Quando você diz o que está sentindo, ela fala que você está bem, que não tem nada e que é coisa da sua cabeça. Ela trata a gente como bicho." (Violeta).

"A assistência médica é horrivel! Olhe, aqui tudo é horrivel... às vezes, morro de dor de dente e, como eu estou grávida, a médica da casa fala que não pode dar remédio para dor não e ainda fala que isso é normal da gravidez." (Margarida).

De acordo com Galvão e Davim, cerca de $80 \%$ das mulheres encarceradas não tiveram acesso a um acompanhamento médico durante a gestação e os $20 \%$ restantes, possuíram, aproximadamente, duas consultas. Assim, pode-se concluir que a falta de pré-natal interfere diretamente no decorrer da gravidez, já que possibilita a descoberta de empecilhos que possam gerar riscos, além disso, proporciona segurança para a mulher, fator de extrema importância para a manutenção da saúde mental da gestante (Galvão \& Davim, 2013).

$\mathrm{O}$ crescente aumento no número de detentas no sistema prisional brasileiro aumentou, consequentemente, o aumento do numero de bebês nascidos em cárcere (cerca de $30 \%$ entre 2009 e 2012). No entanto, com o passar do tempo, a visão dos direitos humanos sobre a mulher e sobre os direitos reprodutivos também ganharam destaque. O acesso aos cuidados de saúde a essa parcela da população socialmente discriminada é tema central dessas recomendações, garantindo os direitos femininos e direitos reprodutivos como um elemento essencial e necessário para o efetivo cumprimento do direito à saúde.

\section{Resultados e Discussão}

Como resultado obtido das bases de dados utilizadas nesta pesquisa, segue o Quadro 1 que divide por base de dados ecategorias os artigos encontrados.

Quadro 1: Quantitativo de artigos científicos encontrados de acordo com os descritores selecionados.

\begin{tabular}{|l|l|l|l|l|}
\hline \multirow{2}{*}{ DESCRITORES } & \multicolumn{4}{l|}{ ARTIGOS ENCONTRADOS NAS BASES DE DADOS } \\
\cline { 2 - 6 } & SciELO & MEDLINE & LILACS & BDENF \\
\hline Cuidado Pré-natal & 291 & 245 & 1088 & 596 \\
\hline Penitenciárias & 41 & 0 & 200 & 72 \\
\hline Saúde pública & 7.005 & 1.340 & 12.646 & 2.402 \\
\hline Cuidado Pré-natal AND Penitenciárias & 0 & 0 & 7 & 3 \\
\hline Cuidado Pré-natal AND Saúde pública & 72 & 15 & 182 & 87 \\
\hline Penintenciárias AND Saúde pública & 0 & 0 & 0 & 0 \\
\hline $\begin{array}{l}\text { Cuidado Pré-natal AND Penitenciárias } \\
\text { AND Saúde pública }\end{array}$ & 0 & 0 & 1 & 1 \\
\hline
\end{tabular}

Fonte: Autores (2021).

Diante desses resultados, foram encontrados 2 artigos completos, na língua portuguesa, entre 2011 a 2021, nas bases de dados LILACS e BDENF, a respeito da temática abordada. A seguir (Quadro 2) a descrição deles: 
Quadro 2: Publicações encontradas na LILACS e BDENF, com os títulos, autores e ano de publicação.

\begin{tabular}{|c|l|l|l|c|}
\hline $\begin{array}{c}\text { N }{ }^{\circ} \text { DO } \\
\text { ARTIGO }\end{array}$ & TítULO DO ARTIGO & PERIÓDICO & AUTORES & \multicolumn{1}{|c|}{$\begin{array}{c}\text { ANO DE } \\
\text { PUBLICAÇÃO }\end{array}$} \\
\hline 01 & $\begin{array}{l}\text { Pré-natal em unidade básica } \\
\text { de saúde a gestantes em } \\
\text { situação } \\
\text { prisional }\end{array}$ & LILACS & $\begin{array}{l}\text { Fochi MCS, } \\
\text { Silva ARC, } \\
\text { Lopes MHBM. }\end{array}$ & 2014 \\
\hline 02 & $\begin{array}{l}\text { Inclusão das mulheres em } \\
\text { privação de liberdade na } \\
\text { Rede Cegonha }\end{array}$ & BDENF & Ministério da Saúde & 2014 \\
\hline
\end{tabular}

Fonte: Autores (2021).

Frente a esses documentos encontrados, é possível perceber, primeiramente, a situação alarmante que as mulheres gestantes enfrentam em unidades prisionais que não oferecem assistência ao Pré-natal adequadamente. Preocupante também se torna a temática com a evidência da ausência de artigos, nas principais bases de dados, relacionados às questões de saúde da gestante encarcerada.

De acordo com Fochi, Silva e Lopes (2014), a gestação, o parto e o puerpério, são responsáveis por causarem inúmeras mudanças na gestante, tanto as alterações sistêmicas, quanto as psicológicas, já que é um momento especial em que todas as mudanças acontecerão a partir de fatores individuais, culturais, e de relacionamento social. Dessa forma, as gestantes encarceradas precisam de uma atenção diferenciada, em razão das condições desfavoráveis que elas enfrentam. A oferta de cuidados às grávidas em situação de privação de liberdade, deve reconhecer os fatores socioculturais e os intrínsecos à condição de encarceramento (Fochi, 2014).

Nesse cenário, conforme o documento do Ministério da Saúde (MS-2014), a Rede Cegonha surgiu como uma forma de política pública de saúde voltada às mulheres e crianças, visando assegurar a atenção para a saúde durante o pré-natal, parto, puerpério, bem como acompanhar a criança durante os primeiros 2 anos. Atualmente, quase todos os municípios nacionais já seguem a Rede Cegonha. Porém, as mulheres privadas de liberdade ainda apresentam problemas para essa acessibilidade (Brasil, 2014).

Diante disso, a ausência de um Pré-natal de qualidade às gestantes aprisionadas ocasiona várias consequências, tanto às mães, quanto aos bebês. Assim, essas mulheres grávidas enfrentam problemas como: o estresse e a depressão, mudanças hormonais, que apesar de acontecerem em qualquer gestante, as que estão privadas de liberdade lidam com alterações negativas, a nível hormonal, mais intensas, há também uma alimentação pobre em nutrientes essenciais para o bom desenvolvimento do feto. Dessa forma, crescem as chances dessas mulheres apresentarem depressão pós-parto, a qual realmente está mais presente em mulheres com privação de Liberdade (Magalhães, 2020; Carneiro, 2016)

A insuficiência alimentar, enfrentada pelas grávidas nas penitenciárias, ocasionam sérios problemas na saúde do feto, como exemplo: a malformação, em consequência do não fechamento do tubo neural do feto, a qual pode ser evitada, em muitos casos, com a utilização da vitamina B9/Ácido Fólico, assim como, nota-se que o uso de cálcio e potássio desde o início da gravidez ajuda no bom desenvolvimento do feto, principalmente no que se refere ao sistema cardiovascular. No entanto, de acordo com Fochi, Silva e Lopes (2014), as queixas alimentares advindas das gestantes em privação de liberdade são recorrentes, principalmente no que se refere ao ganho exacerbado de peso da gestante, sendo este contraindicado na gravidez.

Conforme o Ministério da Saúde (MS-2014), é importante a inclusão da mulher encarcerada na Rede Cegonha, uma vez que se trata de uma política pública e universal de atenção integral à gestante, parturiente, puérpera e para o bebê. A proposta é ofertar à mulher, bem como ao filho, a possibilidade de acesso a um cuidado humanizado, assim como a testes e informações elucidativas sobre a saúde atual, o planejamento familiar e as IST. Assim, cabe destacar que as pessoas privadas 
de liberdade só são restritas do direito de ir e vir, dessa maneira, possuem direito à saúde, à dignidade e à vida, os quais estão previstos na Constituição Federal (Brasil, 2014). Mas, ainda de acordo com Fochi, Silva e Lopes (2014), as condições insalubres das casas penais e a heterogeneidade das detentas dão margem para alta prevalência de transtornos mentais e comorbidades, superando as taxas da população em geral. Apesar de ser um cenário de aprisionamento, o vínculo mãe-filho é essencial e precisa ser respeitado desde a gestação,bem como a amamentação, fundamental para o adequado desenvolvimento da criança, permitindo assim que a mãe exerça oseu papel de cuidadora primária, sendo ela o principal elo entre o exterior e o bebê, responsabilizando-se em apresentar o mundo ao filho, ou seja, por meio da mãe o bebê conhecerá o novo e se sentirá seguro, demonstrando assim que a mãe permite que seja criada a primeira base das relações da criança com a sociedade (Bruscatto, 2014).

O Brasil, ao se comprometer a alcançar os objetivos do milênio, se responsabilizou pela realização de ações voltadas à saúde das gestantes e das crianças, à redução da mortalidade materna e infantil e também à prevenção do HIV/Aids. Os cuidados assistenciais às gestantes encarceradas são cruciais para que se afirme que todas as mulheres possuem acesso a uma atenção pública à saúde reprodutiva, integral e com qualidade. Logo, as unidades prisionais não podem ser locais que propagam doenças ou que negligenciam a saúde (Brasil, 2014).

Entretanto, tem-se notado que a legislação não está sendo respeitada pelo grande quantitativo dos estados do Brasil. Primeiramente, no que se refere à previsão das seções voltadas a gestantes e parturientes, assim como os berçários para os bebês e as creches às crianças com idade a partir de seis meses até sete anos. Entre os estabelecimentos penais, destacam-se as cadeias públicas, localizadas nos interiores, que não possuem adequada estrutura e necessitam realizar o encaminhamento das gestantes às penitenciárias mais próximas das capitais, causando assim o distanciamento das mães e dos bebês do âmbito familiar. É frequente a existência de somente uma penitenciária feminina por estado, ocasionando, consequentemente, o surgimento de superlotações (Carneiro, 2016).

Por conseguinte, sabe-se que as mulheres precisam realizar o pré-natal, o parto hospitalar, ter um acompanhamento tanto do puerpério quando dos seus filhos até os 2 anos. Diante disso, a maior parte desses procedimentos podem ser executados pela equipe de atenção básica prisional ou ainda pela equipe de saúde do território onde está localizada a unidade prisional. É crucial que os gestores de saúde, bem como os de administração prisional trabalhem em equipe, como por exemplo, o agendamento para o mesmo dia e mesma unidade, de todas as mulheres em privação de liberdade, outra atitude seria deslocar a equipe de saúde responsável pela realização do pré-natal até a unidade prisional, seguindo o que é preconizado pelo atendimento domiciliar, previsto na Atenção básica, por meio da Estratégia de Saúde da Família (ESF) Brasil, 2014).

\section{Conclusão}

A assistência ao pré-natal de qualidade é um direito, assegurado pela Constituição Federal, a qualquer gestante, independentemente de ter tido ou não uma conduta ilícita. As ações referentes aos cuidados, voltados às mulheres grávidas, devem atendê-las considerando-as seres biopsicossociais, ou seja, identificando problemas e propondo melhorias nas esferas biológicas, sociais e psicológicas dessas mulheres.

As gestantes precisam de acompanhamento desde a concepção até iniciar o trabalho de parto, visando assegurar que sejam prevenidas complicações tanto na saúde materna, quanto no desenvolvimento do feto. Entretanto, no Brasil, essas mulheres, alocadas em penitenciárias, enfrentam situações que prejudicam o bem estar, tendo que conviverem em estabelecimentos mistos, superlotados, que ofertam condições precárias de higiene e recursos à saúde. Além da sobrecarga de culpa imposta a elas em decorrência do crime cometido, também sofrem com a violação dos próprios direitos à saúde.

São incontáveis as consequências de uma precariedade da assistência ao pré-natal às gestantes em cárcere privado, sendo essas perpassando pelo surgimento de transtornos mentais, como a depressão e o estresse, o desenvolvimento fetal 
prejudicado pela ausência de nutrientes importantes como o ácido fólico, uma não preparação da mulher para saber lidar com o bebê, a insegurança e também o medo com a nova realidade.

Frente ao exposto, concluímos que as condições insalubres das casas penais trazem sérios riscos à saúde das crianças que são geradas e que nascem nessa situação de privação de liberdade e que as mulheres gestantes não recebem a atenção básica de direito durante o ciclo ge gestação e puerpério, havendo necessidade de um trabalho intersetorial e interprofissional para garantir o acesso à política pública com qualidade. É crucial que novas medidas sejam tomadas na direção das políticas públicas, com olhares às gestantes privadas de liberdade, assim como, estimular esse tema em âmbito acadêmico, a fim de que os estudantes da saúde sejam preparados para serem excelentes profissionais preocupados com a oferta do cuidado de qualidade a todo indivíduo.

Ademais, o presente trabalho gera base para futuros artigos e pesquisas sobre a temática, visto que diante da discussão apresentada, a saúde da mulher em situação de privação de liberdade é deixada de lado, principalmente no que se refere aos cuidados básicos envolvendo pré natal, parto, puerpério e amamentação. Além disso, as pesquisas realizadas podem ser úteis em uma futura intervenção sobre o tema. Como sugestão para os próximos trabalhos, seria importante a utilização de questionários sobre as reais condições de pré-natal e assistência às gestantes em privação de liberdade.

\section{Referências}

Barbosa B.S. (2020) Desafios do cárcere feminino no Brasil: Análise da efetividade da decisão proferida pelo STF no habeas corpus coletivo $n^{\circ} 143.641$ [Trabalho de Conclusão de Curso]. Ijuí-RS: Universidade Regional do Noroeste do Estado do Rio Grande do Sul. Curso de graduação em Direito. Departamento de Ciências Jurídicas e Sociais.

Brasil. Constituição (1988). Constituição da República Federativa do Brasil. Senado Federal. Centro Gráfico.

Brasil. Portaria interministerial n.210/2014( 2014). Cria a Política Nacional de Atenção as Mulheres em Situação de Privação de Liberdade e Egressas PNAMPE, com vistas em qualificar a assistência para mulheres recluas. Departamento Penitenciário Nacional.

Brasil. Ministério da Saúde.(2014) Secretaria de Atenção à Saúde. Departamento de Ações Programáticas Estratégicas. Coordenação de Saúde no Sistema Prisional. Inclusão das Mulheres Privadas de Liberdade na Rede Cegonha/Ministério da Saúde, Secretaria de Atenção à Saúde, Departamento de Ações Programáticas Estratégicas, Coordenação de Saúde no Sistema Prisional. Ministério da Saúde. 16 p.

Botelho L. L. R., Cunha C.C. A. \& Macedo, M. (2011) O método da revisão integrativa nos estudos organizacionais. Gestão e sociedade. Belo Horizonte. 5(11): 121-136.

Bruscato, A.(2014) Creche na Prisão: um direito das mães e crianças. Educação e Cidadania. 13(13).

Carneiro, Z., \& Veríssimo, M. (2016) Gestação e desenvolvimento de bebês em situação de cárcere. Extensão em Ação.

Carvalho, M. L. B., \& Freitas, L. D. A. (2016) As faces e os disfarces dos presídios femininos: violações x direitos.

Davim, B. K. G., \& Lima, C. S. (2016) Criminalidade feminina: Desestabilidade familiar e as várias faces do abandono. Revista Transgressões: Ciências criminais em debate. Natal. 4(2).

Ferreira E. V. (2020) A desigualdade de gênero no cárcere: as particularidades das penitenciárias femininas no Brasil [Trabalho de Conclusão de Curso]. Florianópolis: Universidade do Sul de Santa Catarina. Curso de graduação em Direito.

Fochi M. C. S., Silva A. R. C. \& Lopes M. H. B. M. (2014). Pré-natal em unidade básica de saúde a gestantes em situação prisional. Rev Rene. 15(2): 371-7.

Galvão, M. Davim, R. (2013).. Ausência de assistência à gestante em situação de cárcere penitenciário. Paraná: Universidade Federal do Paraná.

Gomes A. V, Ferreira R. K. A \& Rodrigues C. F. C. (2020). A saúde na vida do cárcere no Brasil e no Tocantins. Research, Society and Development.

Justiça Federal. (2014). Lotação das Penitenciárias no Brasil. Levantamento Nacional de informações penitenciárias.

Magalhães, F. A. (2020). A maternidade no cárcere à luz da criminologia feminista [Trabalho de Conclusão de Curso]. Faculdade de Ciências Jurídicas e Sociais. Curso de graduação em Direito.

Makki, S..H \& Santos M.L.(2010) Gênero e criminalidade: Um olhar sobre a mulher encarcerada no Brasil. Âmbito jurídico.

Ministério Da Justiça E Segurança Pública.(2020) Infopen. Levantamento Nacional de Informações Penitenciárias. Período de janeiro a junho de 2020. Secretaria Nacional de Segurança Pública.

Ministério da Saúde. (2016). Plano Nacional de Saúde de 2016-2019. 
Research, Society and Development, v. 10, n. 9, e57410918189, 2021

(CC BY 4.0) | ISSN 2525-3409 | DOI: http://dx.doi.org/10.33448/rsd-v10i9.18189

Mourão L, Oliveira L, Marques A, Branco J, Guimarães M \& Martins de Deus S. (2015). Promoção da Saúde de Mulheres Encarceradas: Um Relato de Experiência. Teresina. Sanare, Sobral.

Plano Nacional de Saúde no Sistema Penitenciário. Ministério da Saúde, 2005 <http://bvsms.saude.gov.br/bvs/publicacoes/plano_nacional_saude_s istema_penitenciario_2ed.pdf>.

Queiroz N. (2015). Presos que menstruam. Record.

Santana A. T, Oliveira G. R. S. A., \& Bispo T. C. F. (2016). Mães do cárcere: vivências de gestantes frente à assistência no pré- natal. Revista Baiana de Saúde Pública. 40(1)

Silva, E. X., \& Cardoso, S. G. (2020). Pré-natal e puerpério em mulheres privadas de liberdade: assistência de enfermagem prestada [Trabalho de Conclusão de Curso]. Goiânia: Universidade Católica de Goiás. Curso de Enfermagem

Wermuth, M. A. D., \& Nielsson, J. G. (2019). O Habeas Corpus 143.641/SP e a tutela coletiva do status libertatis:condição de possibilidade para a humanização do cárcere feminino no Brasil. Rev. Brasileira de Ciências Criminais.. 152, 89. 